\title{
Behavioral and Biochemical Features of the Course and Surgical Treatment of Experimental Obstructive Hydrocephalus in Young Rats
}

\author{
Marcelo Volpon Santos ${ }^{a}$ b Luiza da Silva Lopes ${ }^{b}$ Hélio Rubens Machado ${ }^{a}$ \\ Ricardo Santos de Oliveira ${ }^{a}$ \\ ${ }^{a}$ Division of Pediatric Neurosurgery, Ribeirão Preto Medical School, University of São Paulo, Ribeirão Preto, Brazil; \\ ${ }^{b}$ Developmental Neuropathology Laboratory, Ribeirão Preto Medical School, University of São Paulo, Ribeirão \\ Preto, Brazil
}

\section{Keywords}

Cytokines · Experimental hydrocephalus · Interleukins ·

Ventricular-subcutaneous shunt

\begin{abstract}
Introduction: Hydrocephalus is a multifactorial disease, affecting the dynamics of cerebrospinal fluid (CSF) and leading to severe neurological impairment in children; in spite of the recent advances in hydrocephalus research, it has many physiopathological aspects that still remain poorly understood, especially after treatment. Objectives: To analyze the clinical, radiological, histopathological, and biochemical aspects of kaolin-induced hydrocephalus in an experimental model, both in the acute phase and after shunt treatment, by means of behavioral tests, magnetic resonance imaging (MRI) scans, histopathological studies, and level of inflammatory interleukins in the CSF. Methods: Seven-day-old Wistar rats were used and subdivided into three subgroups: treated hydrocephalic $(n=24)$, untreated hydrocephalic $(n=$ $17)$, and controls $(n=5)$. The hydrocephalic groups underwent cisternal injection of $15 \%$ kaolin for induction of hydrocephalus at 7 days of age. The treated group was submitted
\end{abstract}

to a ventricular-subcutaneous shunt (VSCS) 1 week after induction. All animals were euthanized at 21 days of age. They underwent motor function and memory testing as well as brain MRI scans. Histopathological analysis for glial fibrillary acidic protein and $\mathrm{Ki}-67$ was done, and CSF was collected for measurement of IL-1 $\beta$, IL- 6 , and TNF- $\alpha$. Results: The average time to reach the water maze platform was highest in the untreated hydrocephalic group. The magnetization transfer rates were 37.21 and 33.76 before and after shunting, respectively. The mean astrocyte counts were $2.45,1.36$, and 90.5 for shunted, untreated, and control animals, respectively. The mean CSF IL- $1 \beta$ concentrations were 62.3 and 249.6 $\mathrm{pg} / \mathrm{mL}$, the average IL- 6 levels were 104.2 and $364.7 \mathrm{pg} / \mathrm{mL}$, and the average TNF-a values were 4.9 and $170.5 \mathrm{pg} / \mathrm{mL}$ for the treated hydrocephalic group and the untreated group, respectively. Conclusions: Pups treated with a CSF shunt showed better performance on memory tests. VSCS did not revert demyelination caused by hydrocephalus. Likewise, reactive astrocytosis and cell proliferation over the germinal matrix were not reversed after shunting. Hydrocephalic animals had raised levels of inflammatory interleukins, which returned to normal after treatment.

(c) 2019 S. Karger AG, Basel

\section{KARGER}

(c) 2019 S. Karger AG, Basel

E-Mail karger@karger.com

www.karger.com/dne
Marcelo Volpon Santos, MD, $\mathrm{PhD}$

Division of Pediatric Neurosurgery, Department of Surgery and Anatomy University Hospital, Ribeirão Preto Medical School, University of São Paulo Av. Bandeirantes, 3900, Monte Alegre, Ribeirão Preto, SP 14040-900 (Brazil) E-Mail marcelovolpon@usp.br 


\section{Introduction}

Hydrocephalus is one of the commonest pathological conditions affecting the central nervous system (CNS) during the neonatal period and infancy. It has an overall estimated incidence of 1:2,000 live births and is associated with about one-third of all CNS congenital malformations $[1,2]$. Hydrocephalus is defined by an increase in the volume of cerebral ventricles secondary to abnormal secretion, circulation, or resorption of cerebrospinal fluid (CSF), leading to raised intracranial pressure and appearance of clinical symptoms and signs [3].

The mechanisms of brain damage in this disease remain widely unclear, in spite of significant advances provided recently by clinical studies and experimental methods [4]. Furthermore, among the currently available therapeutic modalities, shunts are still the option used more often [5]. Nevertheless, it is not possible to ratify that shunts are able to reverse the cellular and biochemical injury caused by hydrocephalus, even with early treatment. Therefore, the present study aimed at analyzing, in the context of experimental hydrocephalus induced in young rats, the effects of an adapted (ventricular-subcutaneous) shunt, specifically on their motor and memory skills, on the microstructural and biochemical alterations seen by means of histological examinations, and on the presence of CSF inflammatory biomarkers.

\section{Methods}

Forty-six Wistar rats were used at 7 days of age; hydrocephalus was induced in all of them, except for controls, by intracisternal injections of kaolin as described previously by Lopes et al. [6]. In this technique, each animal is positioned with a flexed neck to expose the dorsal cervical region. After identification of the space between the inferior rim of the foramen magnum and the cranial border of the first cervical vertebra, a percutaneous suboccipital puncture is performed for slow injection of $0.04 \mathrm{~mL}$ of $15 \%$ kaolin suspended in distilled water, previously sterilized at $60^{\circ} \mathrm{C}$.

Afterwards, animals were divided into three experimental groups: (1) hydrocephalic nontreated (HNT) group ( $n=17)$ : pups were sacrificed 14 days after kaolin injection (at 21 days of age); (2) hydrocephalic treated with ventricular-subcutaneous shunt (HTVSCS) group $(n=24)$ : pups shunted with the ventricular-subcutaneous shunt (VSCS) 7 days after induction of hydrocephalus and sacrificed 7 days after shunting (also at 21 days of age); (3) control group $(n=5)$ : pups sacrificed when 21 days old without having undergone any procedure.

Implantation of the VSCS was performed according to the following steps (Fig. 1) [7]: after intraperitoneal anesthesia with a combination of ketamine $10 \%$ and xylazine $10 \%$ (0.1 and 0.05 $\mathrm{mg} / 100 \mathrm{~g}$ of body weight, respectively) and prophylactic antibiot-

Features of Experimental Obstructive

Hydrocephalus in Rats ics (cefalotin $50 \mathrm{mg} / \mathrm{kg}$, also administered intraperitoneally), a short skin incision was performed over the calvaria $3 \mathrm{~mm}$ from the midline to the right and $2 \mathrm{~mm}$ anterior to the coronal suture, enclosing all layers of the scalp, for exposure of the skull. With the aid of a delicate twist drill ( $1 \mathrm{~mm}$ wide), a burr hole was fashioned and the dura mater was pricked. The right lateral ventricle was then directly punctured with a polypropylene catheter (internal diameter of 0.7 and $8 \mathrm{~mm}$ long), bent at a right angle, and connected to a distal catheter $(8-10 \mathrm{~cm}$ long) which, after tunneling through the cervical subcutaneous tissue, was placed in a pocket created bluntly close to the rat's sacrum. The skin was then closed with 2 or 3 Mononylon 5.0 stitches. A drop of cyanoacrylate glue was laid over the incision.

\section{Motor and Memory Assessment}

All animals underwent motor and memory assessments by means of a modified Morris water maze test. It consists of a round pool (diameter $100 \mathrm{~cm}$, height $50 \mathrm{~cm}$ ) and a transparent platform (diameter $8 \mathrm{~cm}$, height $34 \mathrm{~cm}$ ) positioned $2 \mathrm{~cm}$ underwater. Initially, animals went through an adaptation and training period in which they were let free to swim around the pool, without the platform. Thereafter, the platform was placed into the water tank in one specific quadrant. The pool was stored in a completely dark room, except for a tiny light bulb fixed next to the north side of the tank, so that the pup could identify the reference point to be memorized. The test was then performed on the 10th and 11th postinduction days, when animals were put into the pool in one of the four cardinal points on each of the four consecutive sessions, repeated twice daily. The time needed to reach the platform from the moment they were put in the water was recorded in seconds. A resting break of $15 \mathrm{~s}$ was given between sessions.

\section{Analysis of White Matter Myelination by Magnetic Resonance} Imaging

For this matter we used the magnetization transfer rate (MTR) technique, whose goal is to analyze interactions between nonaqueous hydrogen protons with those moving in water, which are usually not analyzed on conventional magnetic resonance imaging (MRI). Scans were acquired in a 3-Tesla large bore gantry scanner (Philips Achieva ${ }^{\mathrm{TM}}$, Rotterdam, The Netherlands), using a specific coil for small rodents, and performed at 14 days of age. Animals of the shunted group were also scanned 7 days after shunting to assess ventricular size and thus adequate functioning of the catheter. Slice thickness was $1 \mathrm{~mm}$, resulting in a total of 28 slices. As mentioned above, the protocol included a 3D T2weighted image and two identical 3D MTR sequences (Fig. 2). T2-weighted scans were chosen to increase the contrast between CSF and brain matter as well as to provide a precise spatial resolution. Magnetization transfer was used with defined standard pulses on the scanner consisting of 121 perpendicular radiofrequency pulses and four rectangular elements with a duration of $275 \mathrm{~ms}$. Then MTR values on each pixel were calculated using the following equation: MTR $(\%)=($ PIwoMT - PIwMT $) \times 100 /$ PIwoMT, where PIwMT and PIwoMT represent pixel intensity before and after scanning with the MTR protocol, respectively. The MTR was obtained on the coronal plane using previously defined regions of interest, one ventral and one dorsal to the left lateral ventricle, along with the whole brain. Voxel size was $0.3 \times 0.32 \times$ $0.3 \mathrm{~mm}$. 

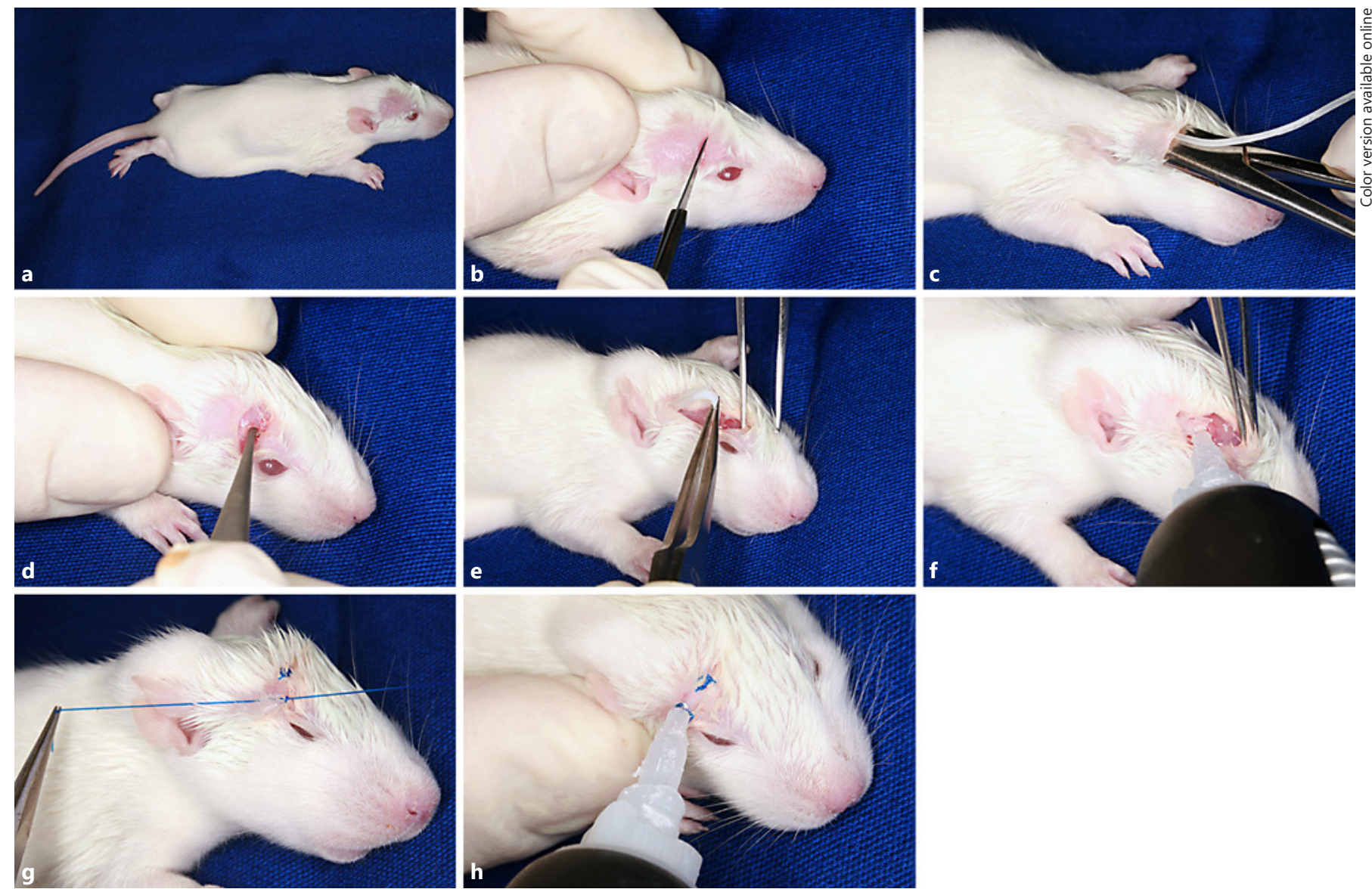

Fig. 1. Sequential iconographic representation of the VSCS technique in a 14-day-old Wistar rat. a Prepping and fur clipping. b Skin incision with a small number 15 scalpel. c Tunneling of the distal catheter. d Burr hole with a 1-mm twist drill. e Ventricular

\section{Sampling}

At the end of all experiments, animals were sacrificed after deep anesthesia with intraperitoneal ketamine and xylazine ( 0.2 and 0.1 $\mathrm{mg} / 100 \mathrm{~g}$ of body weight, respectively). Following transcardiac perfusion with phosphate-buffered saline (PBS), brains were removed en bloc through a vertex craniectomy and fixed in $3 \%$ paraformaldehyde diluted with a $0.1 \mathrm{M}$ phosphate buffer solution $(\mathrm{pH}$ 7.3-7.4). Thereafter, all samples were sectioned on the coronal plane of the optic chiasm, dividing them into anterior (frontal) and posterior (parietal) sections. Subsequently, samples were dehydrated with increasing concentrations of ethanol solutions, diaphanized in xylol, and paraffin soaked.

\section{Immunohistochemistry}

Glial fibrillary acidic protein (GFAP) assays were performed to assess the distribution and morphological aspects of astroglia, as well as Ki-67 for evaluation of the germinal matrix on the external angle of the lateral ventricle.

Samples were initially prepared by extraction of paraffin in a $60^{\circ} \mathrm{C}$ incubator for $30 \mathrm{~min}$ and sequential washouts with xylol and ethanol. After antigenic recovery, when needed, blockage of en- puncture. $\mathbf{f}$ A drop of cyanoacrylate glue was put in to secure the catheter and avoid its migration. $\mathbf{g}$ Skin closure. $\mathbf{h}$ Another drop of glue was placed over the incision. VSCS, ventricular-subcutaneous shunt. dogenous peroxidase was carried out by the acidification and warming technique, with methanol-diluted 3\% hydrogen peroxide. Thereafter, blockage was also performed with adequate serum in $10 \% \mathrm{PBS}$, for $30 \mathrm{~min}$, in a wet chamber. Soon afterwards, these slices were incubated overnight at $4{ }^{\circ} \mathrm{C}$ with the respective primary anti-GFAP antibody 1:300 (DAKO Z0334 ${ }^{\mathrm{TM}}$, Denmark), antiKi-67 1:500 (Santa Cruz Biotechnology SC-23900 ${ }^{\mathrm{TM}}$ ), diluted in bovine serum albumin. Then, the primary antibody was withdrawn, and the appropriate secondary antibody was added (biotinlabeled goat anti-rabbit antibody [Santa Cruz Biotechnology SC$2040^{\mathrm{TM}}$ ] or anti-mouse antibody [Santa Cruz Biotechnology SC$\left.2039^{\mathrm{TM}}\right]$ ), diluted 1:300 in bovine serum albumin. At this point, the assays were incubated with tertiary antibody streptavidin conjugated with horseradish peroxidase (BioLegend ${ }^{\mathrm{TM}}$ cat. 405210), diluted 1:400 in PBS. They were revealed with 3,3-diaminobenzidine (Sigma Aldrich ${ }^{\mathrm{TM}}$, St. Louis, MO, USA). Finally, slides were countercolored with hematoxylin, washed in running water, dehydrated by serial crescent ethanol solutions and xylol, and Permount ${ }^{\mathrm{TM}}$ coverslips were put on.

Photographic documentation was made with an Axioskop 2 plus light microscope (Carl Zeiss ${ }^{\mathrm{TM}}$ ) and an AxioCam HRc digital 


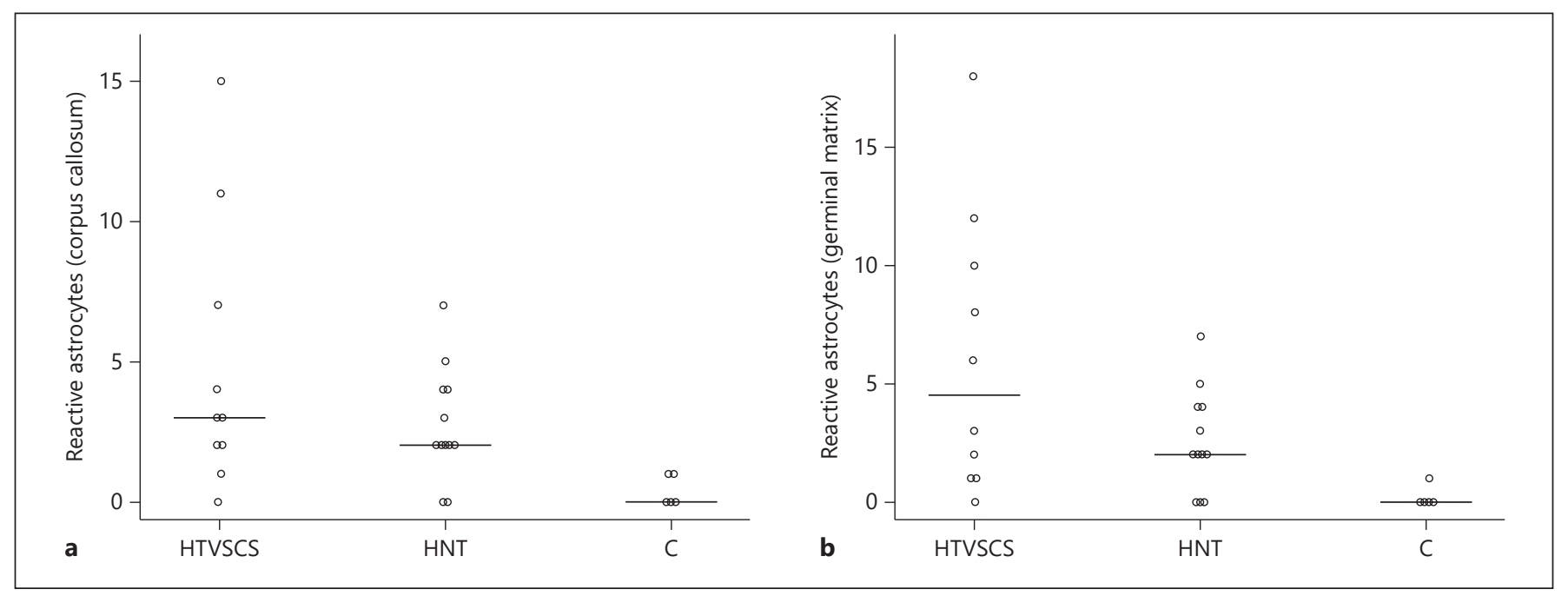

Fig. 2. Number and average number of reactive astrocytes of the experimental groups over the corpus callosum (a) and germinal matrix (b). HTVSCS, hydrocephalic treated with ventricular-subcutaneous shunt; HNT, hydrocephalic nontreated; C, controls.

camera (Carl Zeiss $\left.{ }^{\mathrm{TM}}\right)$, connected to a Pentium II computer equipped with the Axio Vison 3.1 software. The corpus callosum regions, as well as the germinal matrix, of GFAP- and Ki-67-immunomarked slides were also documented, along with cell counting. Cell counting was made on ImageJ software (National Institutes of Health, Bethesda, MD, USA).

\section{CSF Interleukin Levels (IL-1 $\beta, I L-6$, and TNF- $\alpha$ )}

After the vertex craniectomy, prior to removal of the brains, CSF was collected by a direct transcortical ventricular puncture, using a 23-gauge needle and a 1-mL sterile polycarbonate syringe (Becton Dickinson $^{\mathrm{TM}}$, Franklin Lakes, NJ, USA). About $0.25 \mathrm{~mL}$ were withdrawn, which was enough for further analyses. Demonstration of the interleukin levels was performed by commercially available sandwich ELISA kits (all reagents from Abcam ${ }^{\mathrm{TM}}$, Cambridge, UK), according to the manufacturer's instructions, using a rat anti-IL- $1 \beta$ antibody, a mouse anti-IL- 6 antibody, and a rat antiTNF- $\alpha$ antibody.

In 96-well plates (NUNC 442404, Sigma Aldrich ${ }^{\mathrm{TM}}$ ), $50 \mu \mathrm{L}$ of specific antibody for the respective cytokine (IL-1 $\beta$, IL-6, and TNF- $\alpha$ ) were added, diluted in PBS, and incubated overnight at $4{ }^{\circ} \mathrm{C}$. Plates were then washed three times with a solution containing PBS and $0.05 \%$ of the nonionic detergent polyethylene glycol sorbitan monolaurate (Tween 20, Sigma Aldrich ${ }^{\mathrm{TM}}$ ). After that, $100 \mu \mathrm{L}$ of buffer solution (PBS $+1 \%$ of bovine serum albumin) (Thermo Fisher Scientific ${ }^{\mathrm{TM}}$, Waltham, MA, USA) were added so that plates could be incubated for $2 \mathrm{~h}$ at ambient temperature. Another triple wash with PBS and Tween 20 was performed, followed by another incubation at $4{ }^{\circ} \mathrm{C}$ overnight. Subsequently, $50 \mu \mathrm{L}$ of detection antibodies were added and incubated at ambient temperature, plates were triple washed with PBS and Tween 20 again, and mixed with $50 \mu \mathrm{L}$ of avidin-peroxidase. Another triple wash with PBS and Tween 20 was performed. Lastly, the reaction between the content of the plates and $50 \mu \mathrm{L}$ of chromogenic substrate tetramethylbenzidine protected from light was observed for approximately $10 \mathrm{~min}$, until the appearance of a blue color. The reac-

Features of Experimental Obstructive

Hydrocephalus in Rats tion was then interrupted with $50 \mu \mathrm{L}$ of sulfuric acid for reading of its optic density in a spectrophotometer with a wave length of $450 \mathrm{~nm}$. Results were expressed in $\mathrm{pg} / \mathrm{mL}$ for each interleukin.

\section{Statistical Analysis}

Statistical tests for comparisons among groups were chosen as follows: For continuous variables, a linear mixed-effects model for the evaluation of performance in the Morris water maze test and a Student $t$ test for quantification of MTRs were used. For categorical variables, such as GFAP-labeled reactive astrocytes and Ki-67 mitotic cell counts, analysis was performed via double Poisson regression. Regarding the concentration of CSF inflammatory interleukins, after verification that they were not normally distributed, a Kruskal-Wallis test with Dunn's post hoc test and a focused logbinomial Bayesian model were utilized. The statistical softwares SAS 9.2, R 2.15.1 (SAS/STAT ${ }^{\mathrm{TM}}$, Version 9.2, 2008, Cary, NC, USA) and GraphPad Prism ${ }^{\circledR} 6.0$ (GraphPad Software ${ }^{\mathrm{TM}}$, La Jolla, CA, USA) were used. Results were deemed significant when $p$ was $<$ 0.01 .

\section{Results}

\section{Morris Water Maze}

The average time intervals to reach the platform, in the morning (M1, M2) and afternoon (A1, A2) sessions of the 10 th and 11th experimental days, respectively, as well as the standard deviations (SDs), are summarized in Table 1.

The treated (HTVSCS) group did not show better performances (shorter time intervals) when subsequent sessions were compared, nor did the HNT group. Control animals performed gradually better when M2-A1 and 
Table 1. Average time intervals (in s) to reach the water maze platform for the experimental groups

\begin{tabular}{lllr}
\hline Group & Session & Average time & SD \\
\hline HTVSCS & M1 & 41.6 & 8.9 \\
& A1 & 38.8 & 13.2 \\
& M2 & 38.6 & 13.0 \\
& A2 & 36.1 & 12.1 \\
\hline HNT & M1 & 47.5 & 9.8 \\
& A1 & 53.2 & 8.4 \\
& M2 & 51.6 & 6.0 \\
& A2 & 43.1 & 15.5 \\
\hline \multirow{2}{*}{ Controls } & M1 & 44.3 & 12.1 \\
& A1 & 51.6 & 12.4 \\
& M2 & 34.3 & 12.6 \\
\hline
\end{tabular}

A1, afternoon period of the first day; A2, afternoon period of the second day; HNT, hydrocephalic nontreated; HTVSCS, hydrocephalic treated with ventricular-subcutaneous shunt; M1, morning period of the first day; M2, morning period of the second day; SD, standard deviation.

Table 2. MTRs of the whole brain (WB) and dorsal (DR) and ventral (VR) regions of the left lateral ventricle

\begin{tabular}{llll}
\hline Time & Variable & Average MTR & SD \\
\hline Before & WB & 37.21 & 1.82 \\
shunting & DR & 41.07 & 5.9 \\
& VR & 37.06 & 1.48 \\
\hline After & WB & 33.76 & 10.06 \\
shunting & DR & 26.26 & 14.77 \\
& VR & 33.36 & 6.92 \\
\hline
\end{tabular}

MTR, magnetization transfer rate; SD, standard deviation.

Table 3. Average and SD of the number of mitotic cells found in the germinal matrix samples of all experimental groups

\begin{tabular}{lcr}
\hline Group & Average & \multicolumn{1}{c}{ SD } \\
\hline HTVSCS & 2.45 & 3.70 \\
HNT & 1.36 & 2.24 \\
Controls & 90.50 & 22.23 \\
\hline
\end{tabular}

HNT, hydrocephalic nontreated; HTVSCS, hydrocephalic treated with ventricular-subcutaneous shunt; SD, standard deviation.
A1-A2 were compared $(p<0.01)$. Comparison among the performance of the three different groups, however, demonstrated that HTVSCS pups reached the platform more quickly than HNT ones in sessions A1 and M2 $(p<0.01$ for both). Besides that, in session M2, the HNT group's performance was significantly worse than that of controls $(p<0.01)$; HTVSCS animals, on the other hand, performed similarly.

\section{Magnetization Transfer}

All shunted animals included in the study had a clear reduction in ventricular size, as seen in postshunt MRI scans. The preshunt mean ventricular index was 0.67, whereas it became 0.5 after shunting. Average MTRs are described in Table 2. Statistically significant differences were not found in hydrocephalic pups before and after shunting. Comparison among pre- and postshunt MTR rates with controls also failed to show any significant difference, although there seemed to be a tendency towards improved myelination in the whole-brain analyses of the HTVSCS group as compared to the control group ( $p=$ $0.02)$.

\section{Immunohistochemistry Analyses}

Reactive astrocytosis was sought in two distinct regions: corpus callosum and germinal matrix. Average reactive astrocyte count and SDs for all experimental groups are displayed in Figure 2.

These data attest that there were significant differences among all three groups, except for the number of reactive astrocytes in the corpus callosum of the HNT and HTVSCS groups, which tended to be higher in the latter $(p=0.02)$. Therefore, there was no reduction in the number of reactive astrocytes after treatment; conversely, treated animals showed higher counts than untreated ones. Comparatively, one could also observe greater reactive astrocytosis in shunted and unshunted pups than in controls.

Regarding Ki-67 mitotic cell immunolabeling, the average number of marked cells, along with SDs, are summarized in Table 3. Statistically significant differences between the HTVSCS/HNT groups and controls were detected, but not between themselves; ergo, in this study, hydrocephalus reduced the presence of mitotic cells over the germinal matrix, even though treatment with VSCS did not bring any benefits in this regard $(p=0.35)$. It is interesting to point out that, despite the absence of a statistical difference, the number of mitotic cells was greater in the treated group as compared to the untreated one (2.45 vs. 1.36 , SD 3.7 vs. 2.24 , respectively).
38

Dev Neurosci 2019;41:34-43 DOI: $10.1159 / 000497433$
Volpon Santos/da Silva Lopes/Machado/ Santos de Oliveira 
Table 4. Mean CSF concentrations of inflammatory interleukins of treated and untreated hydrocephalic animals

\begin{tabular}{llll}
\hline Group & $\begin{array}{l}\text { Mean IL-1, } \\
\text { pg/mL }\end{array}$ & $\begin{array}{l}\text { Mean IL-6, } \\
\text { pg/mL }\end{array}$ & $\begin{array}{l}\text { Mean TNF- } a, \\
\text { pg/mL }\end{array}$ \\
\hline HTVSCS & 62.3 & 104.2 & 4.9 \\
HNT & 249.6 & 364.7 & 170.5 \\
\hline
\end{tabular}

CSF, cerebrospinal fluid; HNT, hydrocephalic nontreated; HTVSCS, hydrocephalic treated with ventricular-subcutaneous shunt.

\section{CSF Cytokines}

The mean CSF concentrations of the inflammatory interleukins dosed herein are summarized in Table 4. None of the control animals had raised levels of any of the cytokines studied, i.e., CSF concentrations were always zero in this group.

A direct statistical comparison among groups confirmed these data to be significantly different, the HNT group showing the highest levels, significantly higher than those in the HTVSCS and control groups $(p<0.01)$, which, in turn, did not differ between themselves. Nevertheless, all experimental groups had at least one animal in which CSF interleukin concentrations, whether IL-1 $\beta$, IL-6, or TNF- $\alpha$, was null. Therefore, another statistical evaluation using a focused log-binomial Bayesian model was performed, which failed to confirm a strong statistical correlation between raised levels in hydrocephalic pups and their reduction in treated ones, for the number of animals used herein.

\section{Discussion}

The pathophysiology of hydrocephalus, especially in children, remains unknown in various aspects, in spite of important advances achieved in the last decades by centers studying experimental and clinical hydrocephalus. Obviously, this knowledge is essential for the understanding of clinical manifestations of hydrocephalus and might also have therapeutic implications. The development of new treatment modalities should target early physiopathological mechanisms, both on the cellular and molecular levels.

Therefore, the present study aimed at analyzing and correlating clinical, radiological, cellular, and biochemical alterations of hydrocephalus induced by intracisternal kaolin in 7-day-old rats. Injury to the brain parenchyma

Features of Experimental Obstructive Hydrocephalus in Rats was studied and compared to healthy controls; nonetheless, the second and principal objective of this study was to analyze the effect of hydrocephalus treatment by means of a VSCS, with emphasis on short-term recovery of the damage resulting from ventricular dilation and raised intracranial pressure.

The goal of the water maze test is to assess swimming and thus motor skills of rats, along with their ability of spatial location, which also provides information about associative memory [8]. It is a fairly easy test whose main virtue is the possibility of fast training [8]. The disadvantages of the method include the fact that it does not allow motivational variations and is completely manual, which makes evaluations longer. Besides, immersion in water may cause endocrinological and organic distress [9].

In the present work the HTVSCS and HNT groups, when analyzed individually, did not show progressive improvement after training and subsequent sessions in the water maze, contrary to the control group, which showed significantly shorter intervals for reaching the platform as the experiments went on. When comparing all groups, it was noticed that HTVSCS animals had a clearly superior performance in the afternoon session of day 10 and in the morning session of day 11 , along with a tendency to perform better in the afternoon session of day 11. In addition, in the afternoon session of day 11, shunted animals performed rather similarly to controls. Thus, treated animals were able to memorize their way to the platform similarly to healthy controls and more easily than untreated counterparts, indicating reestablishment of spatial memory after shunting.

Del Bigio et al. [10], studying slightly older rats, published analogous results and even pointed out that rats shunted 7 days after hydrocephalus induction had a slightly superior performance than those shunted after 4 weeks. Williams et al. [11] found that it takes more time for hydrocephalic rats to reach the platform 28 days after induction, and that there is a linear correlation between severity of hydrocephalus (according to the degree of ventricular dilation) and poorer results in the water maze test.

Magnetization transfer is a widely used MRI technique for quantification of myelin and the concentration of metabolic products of tissue degradation; many authors have studied MTR in distinct CNS conditions, such as multiple sclerosis, optic neuritis, Wallerian degeneration, and intracranial hemorrhage [12-15]. It is based on the magnetic exchange between protons linked to large, slowmoving molecules (in this case, myelin) and those free in water $[13,14,16]$. MTR is utilized to analyze the exten- 
sion of parenchymal destruction of the brain, since lower MTR levels are attributed to reduction in the integrity of macromolecules, reflecting damage to myelin and to the axonal membrane or presence of inflammatory edema $[13,17]$.

In addition to the whole brain, the dorsal and ventral areas of the lateral ventricle were chosen due to their susceptibility to stretching forces secondary to ventricular dilation, and because, at this age, fibers found at such regions have already become myelinated, according to Jacobson [18]. Nevertheless, no statistically significant differences were found between pre- and postshunt rates nor in the comparison between shunted animals and controls. We postulate that the progression of hydrocephalus in this time schedule was insufficient to produce any lesion detectable by MTR in the periventricular white matter. Some other limitations of MTR application in this context include heterogeneous myelination of the rat's whole brain at this age [18], since MTR techniques compare adjacent cerebral areas, and use of a nonspecific scanner which reduces the sensitivity of MTR $[19,20]$.

Discrepant results have been published in the medical literature in this regard, however. Hähnel et al. [21], analyzing MTR rates in five distinct brain areas of patients with chronic hydrocephalus, observed significantly lower rates in hydrocephalic patients, for all regions except the thalamus, as compared to healthy individuals. They concluded that MTR provides additional information in relation to traditional MRI scans and that there is indeed myelin injury in the white matter, which is in accordance with the findings from Harrison et al. [22]. In the study of Rocha Catalão et al. [4], a functioning shunt returned MTR rates to normal (control) levels in young Wistar rats treated 7 days after hydrocephalus induction with kaolin.

Astrocytes are glial cells widely distributed over the CNS, whose functions include neuronal nutrition and regulation [23]. In situations of CNS distress or injury, they are activated and start to overexpress GFAP, a process called reactive astrocytosis that limits tissular damage and restores homeostasis. The number of reactive astrocytes in all experimental groups was counted in the corpus callosum and germinal matrix, with interesting results: the HTVSCS and HNT groups had increased reactive astrocytes counts in relation to controls, meaning that hydrocephalus activates glial reparatory processes. Surprisingly, HTVSCS rats also had greater counts than HNT counterparts, suggesting that reactive astrocytosis continues even after shunting, and possibly that shunt implantation and presence of a foreign material in the brain has potentiated defensive cellular mechanisms.
These inferences need to be further confirmed by histological evaluations of the shunt implant sites.

Increased density of reactive astrocytes in hydrocephalus, mostly over periventricular white matter, is a wellestablished phenomenon [6,24-26]. Several papers have analyzed the effect of shunting in this context. Rocha Catalão et al. [4] found that the number of reactive astrocytes was elevated in the corpus callosum, external capsule, and germinal matrix of hydrocephalic pups, and reduced after treatment. Miller and McAllister [27] studied GFAP profiles in the H-Tx model of hydrocephalic rats before and after VSCS, and postshunt reductions in GFAP expression of 18,23 , and $18.3 \%$ were seen in the parietal and occipital cortex and periaqueductal white matter, respectively.

Furthermore, Ki-67 immunolabeling was studied in order to evaluate cell proliferation over the germinal matrix (located in the external angle of the lateral ventricles). This is a protein expressed in all phases of the mitotic cycle, whereas it is absent in cells which are not replicating (G0); for this reason, it is considered an excellent marker to specify the growth fraction of a given tissue [28, 29]. We observed that controls had intense cellularity in this region, with a great number of labeled cells, whereas hydrocephalic pups, treated or not, showed less evident labeling; objective counting confirmed fewer Ki-67marked cells in these latter groups, which did not differ between each other. This is a strong indicator that hydrocephalus reduces cell proliferation in the germinal matrix, and shunting does not seem to reverse this phenomenon. To the best of our knowledge, there are no other studies which addressed the effects of shunting in these circumstances, although there are some papers describing a reduction of $\mathrm{Ki}-67$-labeled cells in purely untreated hydrocephalic rats $[6,24,26]$.

Lastly, the final analysis of this study concerned the role of inflammatory mechanisms in the pathophysiology of hydrocephalus. Interleukins comprise a group of cytokines that mediate and trigger inflammatory responses among various types of cells [30]. The immature CNS is particularly vulnerable to inflammation-related injury [31]. Proinflammatory cytokines are produced by T lymphocytes, and when released, they promote migration of immune cells into the brain as well as microglial and astrocyte activation [31]. T lymphocytes have been found to migrate across the choroidal epithelium forming the blood-CSF barrier and to inspect the CNS environment for cognate antigens along perivascular spaces $[19,20]$.

Although the level of specific interleukins such as insulin-like growth factor 1 , hepatocyte growth factor, vas-
Volpon Santos/da Silva Lopes/Machado/ Santos de Oliveira 
cular endothelial growth factor, interferon-gamma, and IL-18 is known to be raised in patients with neonatal hydrocephalus, their role has not been completely clarified $[2,31,32]$. Few papers have addressed this issue, and the majority of these studied inflammation in patients with normal-pressure hydrocephalus, which is a condition specific of the elderly and might not represent other types of hydrocephalus [33-36].

Moreover, there is scarce information regarding the consequences of shunt therapy. Despite the increase in cerebral perfusion and the reduction in mechanisms of direct injury that shunting brings, it does hinder inflammatory mechanisms specifically, and therefore microglial damage can continue even after the intervention [31]. Since they constitute biomarkers whose levels can be measured, interleukins could also help in the diagnosis and evaluation of the efficacy of treatment [37].

We selected three interleukins, based on previous studies and the individual features of each cytokine: IL$1 \beta$, IL- 6 , and TNF- $\alpha$. IL- $1 \beta$ increases the proliferation, differentiation, and production of antibodies by B lymphocytes and also has proinflammatory activity within the CNS, such as induction of neurodegeneration and fever [33]. IL-6 is produced by T lymphocytes in response to antigenic stimuli and acts on late stages of $B$ cell differentiation [38]; its blockage leads to a reduction of neuronal regeneration mechanisms [39]. TNF- $\alpha$ is the key initiator of immune-mediated inflammation in the brain and has intense expression in neurodegenerative diseases such as multiple sclerosis, Alzheimer's disease, and vascular dementia [35, 36]. These three markers have all been implicated in inflammatory cerebral injury $[19,33$, $36,38]$.

The results of this study suggest that there is an increase in the abovementioned interleukins in kaolin-induced hydrocephalus and that treatment with VSCS reduced their levels, indicating that inflammation might be part of the physiopathology of hydrocephalus. In the medical literature, there are very few studies exploring the relation between interleukins and experimental hydrocephalus; nevertheless, there is only one study analyzing the effects of treatment with shunts. Wostrack et al. [40] measured CSF concentrations of IL- 6 in 84 patients with posthemorrhagic hydrocephalus. They found that IL-6 concentrations were clearly elevated and that they correlated with shunt dependency, along with progression of the disease. They also stated that high IL-6 levels might predict the need for shunting.

Merhar [30], in a meta-analysis of inflammatory biomarkers in neonatal hydrocephalus, mentions two other studies: the one by Sävman et al. [35], which found high levels of IL- $1 \beta$, IL-6, IL- 8 , and TNF- $\alpha$ in preterm children with germinal matrix hemorrhage, and the one by Schmitz et al. [38], who reported raised concentrations of this interleukin and interferon-gamma in the same setting.

Generally speaking, there is a gradually bigger body of evidence confirming the occurrence of inflammation in hydrocephalus, consequently elevating the levels in CSF interleukins. Studies with larger samples, alongside correlation with clinical hydrocephalus, are certainly necessary. The possibility of measuring the concentrations of these markers in CSF and blood is also a potential target for future research.

\section{Conclusion}

The VSCS for treatment of kaolin-induced hydrocephalus, for the time intervals used herein, was able to improve memory performance in rats. Contrarily, periventricular white matter myelination, as evaluated by magnetization transfer techniques, is damaged by hydrocephalus and is not restored after shunting. Likewise, shunt treatment was not sufficient to enable reduction of reactive astrocytosis processes within periventricular regions and cell proliferation over the germinal matrix. Finally, kaolin-induced hydrocephalus in rats increases the CSF levels of inflammatory interleukins IL- $1 \beta$, IL- 6 , and TNF- $\alpha$, and VSCS reduced these levels, indicating the presence of inflammation processes in the physiopathology of this condition.

\section{Acknowledgments}

The authors would like to acknowledge Camila Araujo Bernardino Garcia, Thais Helena Romeiro, and Evelise Jardini for their help in preparing animals for surgery. They would also like to thank Rodrigo Antonio Pessini for processing the MRI magnetization transfer studies and Davi Casale Aragon for his invaluable assistance with the statistical analyses.

\section{Statement of Ethics}

All experimental and surgical procedures involving animals were strictly in accordance with the guidelines of the Brazilian Society of Laboratory Animal Science (SBCAL) and the Brazilian College of Animal Experimentation (COBAL), and approved by the Animal Experimentation Ethics Committee at the authors' institution. 


\section{Disclosure Statement}

The authors have no conflicts of interest to declare.

\section{Funding Sources}

No financial funding or sponsorship was received for this study.

\section{Author Contributions}

Conception and design: M. Volpon Santos, L. da Silva Lopes, and R. Santos de Oliveira. Acquisition of data: M. Volpon Santos and L. da Silva Lopes. Analysis and interpretation of data: M. Volpon Santos and R. Santos de Oliveira. Drafting of the article: all authors. Critical revision of the article: L. da Silva Lopes, R. Santos de Oliveira, and H.R. Machado. Review of the final version of the manuscript and approval for submission: all authors.

\section{References}

1 Bondurant CP, Jimenez DF. Epidemiology of cerebrospinal fluid shunting. Pediatr Neurosurg. 1995;23(5):254-8; discussion 259.

2 Lam S, Harris D, Rocque BG, Ham SA. Pediatric endoscopic third ventriculostomy: a population-based study. J Neurosurg Pediatr. 2014 Nov; 14(5):455-64.

3 Williams MA, McAllister JP, Walker ML, Kranz DA, Bergsneider M, Del Bigio MR, et al. Priorities for hydrocephalus research: report from a National Institutes of Healthsponsored workshop. J Neurosurg. 2007 Nov; 107(5 Suppl):345-57.

4 Rocha Catalão $\mathrm{CH}$, Leme Correa DA, Bernardino Garcia CA, dos Santos AC, Garrido Salmon CE, Alves Rocha MJ, et al. Pre- and postshunting magnetization transfer ratios are in accordance with neurological and behavioral changes in hydrocephalic immature rats. Dev Neurosci. 2014;36(6):520-31.

5 Drake JM. The surgical management of pediatric hydrocephalus. Neurosurgery. 2008 Feb; 62 Suppl 2:633-40; discussion 640-2.

6 Lopes LS, Slobodian I, Del Bigio MR. Characterization of juvenile and young adult mice following induction of hydrocephalus with kaolin. Exp Neurol. 2009 Sep;219(1): 187-96.

7 Santos MV, Garcia CA, Jardini EO, Romeiro TH, da Silva Lopes L, Machado HR, et al. Ventricular-subcutaneous shunt for the treatment of experimental hydrocephalus in young rats: technical note. Childs Nerv Syst. 2016 Aug;32(8):1507-11.

8 Morris R. Developments of a water-maze procedure for studying spatial learning in the rat. J Neurosci Methods. 1984 May;11(1):4760.

9 Vorhees CV, Williams MT. Morris water maze: procedures for assessing spatial and related forms of learning and memory. Nat Protoc. $2006 ; 1(2): 848-58$.

10 Del Bigio MR, Crook CR, Buist R. Magnetic resonance imaging and behavioral analysis of immature rats with kaolin-induced hydrocephalus: pre- and postshunting observations. Exp Neurol. 1997 Nov;148(1):256-64.

11 Williams MT, Braun AA, Amos-Kroohs RM, McAllister JP 2nd, Lindquist DM, Mangano FT, et al. Kaolin-induced ventriculomegaly at weaning produces long-term learning, mem- ory, and motor deficits in rats. Int J Dev Neurosci. 2014 Jun;35:7-15.

12 Corkill RG, Garnett MR, Blamire AM, Rajagopalan B, Cadoux-Hudson TA, Styles P. Multi-modal MRI in normal pressure hydrocephalus identifies pre-operative haemodynamic and diffusion coefficient changes in normal appearing white matter correlating with surgical outcome. Clin Neurol Neurosurg. 2003 Jul;105(3):193-202.

13 Grossman RI, Gomori JM, Ramer KN, Lexa FJ, Schnall MD. Magnetization transfer: theory and clinical applications in neuroradiology. Radiographics. 1994 Mar;14(2):279-90.

$14 \mathrm{Hu} \mathrm{Y,} \mathrm{Chowdhry} \mathrm{S,} \mathrm{Robinson} \mathrm{S.} \mathrm{Infantile}$ Posthemorrhagic Hydrocephalus. In: Winn HR, editor. Youmans Neurological Surgery. Philadelphia: Elsevier Saunders; 2011. p. 1987-92.

15 Yamada H, Yokota A, Furuta A, Horie A. Reconstitution of shunted mantle in experimental hydrocephalus. J Neurosurg. 1992 May; 76(5):856-62.

16 Gozzi M, Nielson DM, Lenroot RK, Ostuni JL, Luckenbaugh DA, Thurm AE, et al. A magnetization transfer imaging study of corpus callosum myelination in young children with autism. Biol Psychiatry. 2012 Aug;72(3): 215-20.

17 Newbould RD, Nicholas R, Thomas CL, Quest R, Lee JS, Honeyfield L, et al. Age independently affects myelin integrity as detected by magnetization transfer magnetic resonance imaging in multiple sclerosis. Neuroimage Clin. 2014 Mar;4:641-8.

18 Jacobson S. Sequence of myelinization in the brain of the albino rat. A: cerebral cortex, thalamus and related structures. J Comp Neurol. 1963 Aug;121(1):5-29.

19 Strazielle N, Creidy R, Malcus C, Boucraut J, Ghersi-Egea JF. T-lymphocytes traffic into the brain across the blood-CSF barrier: evidence using a reconstituted choroid plexus epithelium. PLoS One. 2016 Mar;11(3): e0150945.

20 Lyman D. A case and literature review of normal pressure hydrocephalus in mixed connective tissue disease. Caspian J Neurol Sci. 2016;2(6):42-50.

21 Hähnel S, Münkel K, Jansen O, Heiland S, Reidel M, Freund M, et al. Magnetization trans- fer measurements in normal-appearing cerebral white matter in patients with chronic obstructive hydrocephalus. J Comput Assist Tomogr. 1999 Jul-Aug;23(4):516-20.

22 Harrison NA, Cooper E, Dowell NG, Keramida G, Voon V, Critchley HD, et al. Quantitative Magnetization Transfer Imaging as a Biomarker for Effects of Systemic Inflammation on the Brain. Biol Psychiatry. 2015 Jul;78(1): 49-57.

23 Ben Haim L, Carrillo-de Sauvage MA, Ceyzériat K, Escartin C. Elusive roles for reactive astrocytes in neurodegenerative diseases. Front Cell Neurosci. 2015 Aug;9:278.

24 Del Bigio MR, Zhang YW. Cell death, axonal damage, and cell birth in the immature rat brain following induction of hydrocephalus. Exp Neurol. 1998 Nov;154(1):157-69.

25 Deren KE, Packer M, Forsyth J, Milash B, Abdullah OM, Hsu EW, et al. Reactive astrocytosis, microgliosis and inflammation in rats with neonatal hydrocephalus. Exp Neurol. 2010 Nov;226(1):110-9.

26 Di Curzio DL, Buist RJ, Del Bigio MR. Reduced subventricular zone proliferation and white matter damage in juvenile ferrets with kaolin-induced hydrocephalus. Exp Neurol. 2013 Oct;248:112-28.

27 Miller JM, McAllister JP 2nd. Reduction of astrogliosis and microgliosis by cerebrospinal fluid shunting in experimental hydrocephalus. Cerebrospinal Fluid Res. 2007 Jun;4(1):5.

28 Jalava P, Kuopio T, Juntti-Patinen L, Kotkansalo T, Kronqvist P, Collan Y. Ki67 immunohistochemistry: a valuable marker in prognostication but with a risk of misclassification: proliferation subgroups formed based on Ki67 immunoreactivity and standardized mitotic index. Histopathology. 2006 May; 48(6):674-82.

29 Polley MY, Leung SC, Gao D, Mastropasqua MG, Zabaglo LA, Bartlett JM, et al. An international study to increase concordance in Ki67 scoring. Mod Pathol. 2015 Jun;28(6): 778-86.

30 Merhar S. Biomarkers in neonatal posthemorrhagic hydrocephalus. Neonatology. 2012; 101(1):1-7.

31 Sofroniew MV. Molecular dissection of reactive astrogliosis and glial scar formation. Trends Neurosci. 2009 Dec;32(12):638-47. 
32 Naureen I, Waheed KA, Rathore AW, Victor S, Mallucci C, Goodden JR, et al. Fingerprint changes in CSF composition associated with different aetiologies in human neonatal hydrocephalus: inflammatory cytokines. Childs Nerv Syst. 2014 Jul;30(7):1155-64.

33 Scollato A, Terreni A, Caldini A, Salvadori B, Gallina P, Francese S, et al. CSF proteomic analysis in patients with normal pressure hydrocephalus selected for the shunt: CSF biomarkers of response to surgical treatment. Neurol Sci. 2010 Jun;31(3):283-91.

34 Sival DA, Felderhoff-Müser U, Schmitz T, Hoving EW, Schaller C, Heep A. Neonatal high pressure hydrocephalus is associated with elevation of pro-inflammatory cytokines
IL-18 and IFNgamma in cerebrospinal fluid. Cerebrospinal Fluid Res. 2008 Dec;5(1):21.

35 Sävman K, Blennow M, Hagberg H, Tarkowski E, Thoresen M, Whitelaw A. Cytokine response in cerebrospinal fluid from preterm infants with posthaemorrhagic ventricular dilatation. Acta Paediatr. 2002;91(12):135763.

36 Tarkowski E, Tullberg M, Fredman P, Wikkelsö C. Normal pressure hydrocephalus triggers intrathecal production of TNF-alpha. Neurobiol Aging. 2003 Sep;24(5):70714.

37 Tarnaris A, Toma AK, Chapman MD, Petzold A, Kitchen ND, Keir G, et al. The longitudinal profile of CSF markers during external lum- bar drainage. J Neurol Neurosurg Psychiatry. 2009 Oct;80(10):1130-3.

38 Schmitz T, Heep A, Groenendaal F, Hüseman D, Kie S, Bartmann P, et al. Interleukin-1beta, interleukin-18, and interferon-gamma expression in the cerebrospinal fluid of premature infants with posthemorrhagic hydrocephalus - markers of white matter damage? Pediatr Res. 2007 Jun;61(6):722-6.

39 Zhang JM, An J. Cytokines, inflammation, and pain. Int Anesthesiol Clin. 2007;45(2):27-37.

40 Wostrack M, Reeb T, Martin J, Kehl V, Shiban E, Preuss A, et al. Shunt-dependent hydrocephalus after aneurysmal subarachnoid hemorrhage: the role of intrathecal interleukin-6. Neurocrit Care. 2014 Aug;21(1):78-84. 